\title{
A Brief Discussion on the Origin and Diachronic Evolution of the Chinese "not only p, but also q"
}

\author{
Xiaoyan Cao \\ School of Literature \\ South China Normal University \\ Guangzhou, China
}

\begin{abstract}
The Chinese sentence pattern "not only p, but also $q$ " is originated from the sentence pattern "not only $p$, but $q^{\prime \prime}$ in the Western Han Dynasty. After long-term development and change, the sentence patterns such as "not only p, also q", "not only $p$, and $q$ " and "not merely $p$, but $q$ " has appeared successively. It was initially formed in the Qing Dynasty and developed rapidly during the Republic of China.
\end{abstract}

Keywords-progressive compound sentences; "not only p, but also q"; origin; evolution

\section{INTRODUCTION}

Progressive compound sentences are also called progressive complex sentences and advanced complex sentences, which refer to the sentences of which the latter clause has deeper meaning than the former clause in terms of scope, degree, quantity, time, etc. ${ }^{1}$ The main formats include "not only p, even (also) q", "let alone p, even (also) q", "not only p, even q", "not only p, but q". Among them, "not only $\mathrm{p}$, but $\mathrm{q}^{\prime}$ is the representative format of the progressive compound sentence. The conjunction "not only" is used in the former clause of the joint compound sentence that expresses the progressive meaning. The whole sentence points out and acknowledges the meaning of clause led by "not only", and indicates that this is not the whole meaning of the speaker. The meaning in the latter clause is deeper than the former one. ${ }^{2}$ The conjunction "but also" is used to connect words, phrases, clauses or sentences, indicating that the meaning of the latter component is more than that of the former component and has the effect of strengthening the energy in language. ${ }^{3}$

\section{The ORIGIN OF THE ChINESE SENTENCE "NOT ONLY P, BUT ALSO Q"}

We know that before the formation of the Chinese sentence pattern "not only p, but also q", other forms of the

Zhang Bin. Modern Chinese Descriptive Grammar [M]. Beijing: The Commercial Press, 2015: 650.

2 Department of Chinese Language, Peking University, 1955, 1957 Language Class Compilation. Explanation of Modern Chinese Function Words [M]. Beijing: Commercial Press, 1982: 95.

Department of Chinese Language, Peking University, 1955, 1957 Language Class Compilation. Explanation of Modern Chinese Function Words [M]. Beijing: Commercial Press, 1982: 184. sentence pattern expressing "progressive meaning" appeared in ancient Chinese.

\section{A. In the Western Han Dynasty, the Phrase "not only p, but q" Appeared}

The Chinese sentence "not only p, but also q" was first originated from the "not only $\mathrm{p}$, but q" format in the Western Han Dynasty. For example, He Yan in the period of the Three Kingdoms said in "Interpretation of The Analects of Confucius-advanced": "Zizhang asked how to be a good person. Confucius said if a good person doesn't go forward according to the experience of former people, he can't achieve good learning. Kong said that practice is following. If good people do not only follow the old traces, they can seldom start a business, let alone having the sage's position. Kong in this case refers to Kong Anguo of the Western Han Dynasty. The previous clause led by "not only" is based on affirmative meaning, and the latter clause led by adverb "also" moves forward.

Another example is in He Yan in the Three Kingdoms Period in the Analects of Confucius-Bayi: "Confucius said that in shooting, it is not important to shoot through the target." [Ma said: Shooting has five good deeds, the shooter doesn't think shooting through the target is good, but shooting on the middle.] "Ma" in this case refers to $\mathrm{Ma}$ Rong of the Eastern Han Dynasty. It can be seen from this that during the Eastern Han Dynasty, there were also cases of the format "not only p, but also q". Another example is the "Full Liang Articles" of the Six Dynasties: "And the consultation: the vulgar is not only a jagged, but also a vain. Why do not solve the problem without dispelling it?"

\section{B. During the Wei, Jin and Southern and Northern} Dynasties, the Sentence "not only p, also q" Appeared

(1) The people know these methods don't need to use marquises. The elixir can not only offer longevity, but also can be gold. If it is made, we first use a hundred pounds to set up a big sacrifice. ("Bao Puzi-Internal" Volume 4)

During this period, the sentence "not only p, also q" was not common. This example appeared only in "Bao Puzi", and this sentence was rarely seen in other documents of the same period. 


\section{In the Yuan Dynasty, the Phrase "not only p, but also q" Appeared}

(2) If you can marry to him, not only will you have a good reputation, but you will be able to benefit from it forever. ("Selected Works of the Yuan Dynasty, Yutangchun meet the husband")

During this period, the phrase "not only p, but q" was rare. This case only appeared in the "Selected Works of the Yuan Dynasty", and this sentence was rarely seen in other documents of the same period.

D. In the Ming Dynasty, "not only p, but (also) q", "not only $p$, also (and // and //) q and other Sentence Patterns Appeared

(3) In the Tang Dynasty, Ji Yun said: Prime Minister Pei Guangting married the daughter of Wu Sansi, and Gao Lishi had adultery with him. He not only has a legal wife, but also has illegal love affair. ("Wan Li compilation" volume six)

(4) If it is a phoenix nest, there must be treasure. There not only should be eggs, but also some treasure. (The "Sambo Treasure Western Record" fifty-second chapter)

(5) He rise up at once and worship the earth road: "The taste of Duomengxian sweet fruit not only relieve the hunger and thirst, but also make me realize the prelife. However, since the prelife are so precious, I don't know what sin I have made, so that I was revenged in this life, and there is no end." (Amazing Tales" Volume 24)

(6) Zhuzhu and Yulang are all born with the same beauty, as if they are made from nice jade and the white powder. In addition, they are clever in nature. The men are good at study and women are good at needlework. There is another one, they not only are good-looking and talented, but also have filial piety. Don't mention the gossip. ("Words to Live By" volume 8)

(7) The waiter went to tell the neighboring people and firstly sent Ye Huoer Yao Wang to inquire the authenticity. He said: "Not only are the women beautiful, but they also riding a horse alone. We don't need to be afraid. ("Ordinary Words to Warn the World" Volume 21)

(8) The elders in Luoyang are in large numbers. They all sigh that Liu Gong not only has virtue, but also can identify good people. ("Slapping the table in amazement, Part" volume 22)

During this period, there were a variety of formats that were similar to the "not only p, but also q" sentences and express progressive meaning. In the sentence patterns "not only p, but (also) q", "not only p, but also (and/even/also)", the conjunctions "and", "also", "but", "even" and "but also" express the meaning of "also".

\section{E. In the Qing Dynasty, "not only p, and q", "not only p, but (also) q" Appeared}

(9) At this time, Ma Qiang went to the house of his teacher at this time. He not only searched the Duan inkstand, but also grabbed $\mathrm{Zhu} \mathrm{Xi}$ and wanted to take her as a concubine. (Chapter 73 of "The Seven Heroes and Five Meanings")

(10) Yan officer not only didn't blame, but also said many encouraging words: "When the work of Jun River id completed, you will also be rewarded. (Chapter 86 of "The Seven Heroes and Five Meanings")

(11) When I arrived at the kitchen, there are ready-made candles, and after looking carefully, there are not only meals and bread, but also a bottle of good liquor. (Chapter 114 of "The Seven Heroes and Five Meanings")

(12) Bao Zheng secretly nodded, saying: "He not only has good fortune, but also abides by rules. It's a blessing to the soul, which it's good." (Chapter 17 of "The Seven Heroes and Five Meanings")

(13) Unexpectedly, all the words were heard by Jiao Dapeng, and he thought: "This is actually the partisan of King Ning. He used the trick to attack Suzhou. If I don't save it, not only will Yu Qian's life be difficult to protect, but the Suzhou people will be killed by him, which will be hard to imagine." (Chapter 65 of "The Seven Heroes and Five Meanings")

(14) Qiu Lian said: "That is not only an apprentice, but also the child Min Ling of the younger brother." ("The Three Knight Sword" Chapter 26)

In the sentence patterns "not only p, and q", "not only $p$, and (still) q", "and", "and also" express the meaning of "but also".

It can be seen from the above that the Chinese sentence "not only p, but also q" was originally originated in the "not only p, but q" format in the Western Han Dynasty.

\section{The DiAChronic Evolution OF THE ChINESE SENTENCE "NOT ONLY P, BUT ALSO Q"}

The Chinese "not only p, but also q" sentence appeared in the "Theory of Song Dynasty" (Vol. 14) of Wang Fuzhi in the Qing Dynasty: "The left and right sides refused to vacate Huai, Yi, Chu, and Xi. It not only defeated Jin, but also can contend against Mongolia." In this sentence, the latter clause connected by the conjunction "but also" has deeper meaning than the former clause led by the conjunction "not only", which is a typical progressive compound sentence. In Wang Fuzhi's "Theory of Song Dynasty", the author only found only one case of this Chinese sentence "not only p, but also q".

The Chines sentence pattern "not only p, but also q" has experienced a long period of diachronic evolution, which can be divided into two periods: the formation period and the development period.

\section{A. Formation Period: Qing Dynasty}

In the Qing Dynasty, the Chinese sentence pattern "not only p, but also q" was initially formed. During this period, the earliest use case of Chinese sentence pattern "not only $p$, but also q" not only appeared in "Theory of Song Dynasty", but the cases of Chinese sentence pattern "not only $p$, but 
also q" also appeared in other ancient books, which is not common. For example:

(15) He originally planned to taunt, but when he met Yan Sheng, who is not only well-dressed, but also looks beautiful and talks elegantly, he feels uneasy, self-defeating, and ashamed. He can't even say a whole word. (Chapter 35 of "The Seven Heroes and Five Meanings")

(16) Now if you don't go to Kaifeng Prefecture, you will not only betray the other brothers, but also be sorry to the brothers of home. What is your personal loyalty? (Chapter 57 of "The Seven Heroes and Five Meanings")

(17) If you take this action, you will not only kill vermin for the people, but also remove the harmful things for the country. (Chapter 60 of "The Seven Heroes and Five Meanings")

(18) After Yang Fang heard that Ni Taigong not only stayed, but also named Ni Zhong, he went forward and said:
"I would like to kowtow and congratulate Taigong. (Chapter 71 of "The Seven Heroes and Five Meanings")

(19) It should be the whole pieces of classics of Confucius. Not only the texts of "Yu Dian" and "Nine Coins" and the end of the Western Han Dynasty, but also the absence of Kong Anguo is also among them. ("general introduction of the five classics")

(20) Su Shi was afraid at first, and later felt the sweet taste. She was very happy. She not only don't feel afraid, but also look forward to staying longer. (Chapter 63 of "The Seven Heroes and Five Meanings")

(21) Jia Zhen stands up and said smiling: "This is a big progress. Not only the style is good, but the bow also has a strength. (Chapter 75 of "The Red Mansion")

In order to fully explain the use of the sentence patterns "not only p, but also q" in the Qing Dynasty, we take the fifteen ancient books before and after this period as examples in "Table I":

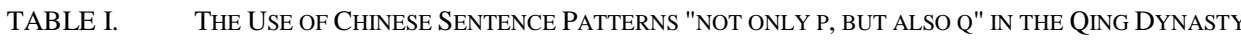

\begin{tabular}{|c|c|c|c|c|c|}
\hline The title of books & not only p, also q & not only $p$, and also $q$ & not only $p$, but $q$ & not only $p$, and $q$ & not only $p$, and $q$ \\
\hline The Seven Heroes and Five Meanings & 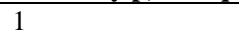 & 0 & 0 & 2 & 16 \\
\hline The Travels of Lao Ts'an & 0 & 0 & 0 & 0 & 0 \\
\hline A Dream in Red Mansions & 0 & 3 & 5 & 0 & 11 \\
\hline The Travels of Lao Ts'an & 0 & 0 & 0 & 0 & 0 \\
\hline $\begin{array}{c}\text { Comment on Romance Biography of } \\
\text { the Tang Dynasty }\end{array}$ & 0 & 0 & 0 & 0 & 1 \\
\hline Suet Gwong Fan Tong & 0 & 0 & 0 & 0 & 1 \\
\hline $\begin{array}{c}\text { Strange Stories from a Scholar's } \\
\text { Studio }\end{array}$ & 0 & 0 & 0 & 0 & 0 \\
\hline Embroidered YunGe & 0 & 1 & 0 & 0 & 1 \\
\hline A Dream in Red Mansions & 1 & 7 & 5 & 0 & 11 \\
\hline Judge Dee & 0 & 3 & 0 & 0 & 4 \\
\hline Xiang Military Record & 0 & 0 & 1 & 0 & 0 \\
\hline Unofficial history of the Qing dynasty & 0 & 2 & 0 & 0 & 1 \\
\hline The One Year of the Sea Kingdom & 0 & 5 & 0 & 0 & 1 \\
\hline
\end{tabular}

It can be seen from "Table I" that in the Qing Dynasty, the use of Chinese sentence pattern "not only p, but also q" was slowly developing in a growing trend. At the same time, the "not only $\mathrm{p}$, and $\mathrm{q}$ " sentence pattern shows a strong development trend, and the developing momentum of "not only p, but q", "not only p, and also q", "not only p, still q" sentence pattern is relatively weak. It can be seen that the Qing Dynasty is the formation period of the Chinese sentence pattern "not only p, but also q".

\section{DEVELOPMENT PERIOD: REPUBLIC OF CHINA}

During the Republic of China, the Chinese sentence pattern "not only p, but also q" has been further developed, and its breadth in use far exceeds the Qing Dynasty. For example:

(22) Why don't we ennoble them as male lords and make them serve as servants. In this way, we not only favored courtier, but also won't hurt the mother's heart. ("Ancient and Modern Love")

(23) "The Narrative of the Window": Li Yuan's family has a beautiful woman named Zhenzhu. This girl is not only beautiful, but also considerate. ("Ancient and Modern Love")

(24) There was a prostitute named Huang Xiuyun in $\mathrm{Wu}$ Zhong. She is not only beautiful, but also smart with ideas. ("Ancient and Modern Love")

(25) With the word "clear and honest", he has been the Governor of Guangdong and Guangxi. He not only love the people like his children, but also be seek talent with eagerness. (Chapter 5 "The Third Talents of the Qing Dynasty")

(26) Since the emperor's ascension, he has changed his habit of keeping his integrity. He is very promiscuous, but also moody and murderous. "The Third Talents of the Qing Dynasty" 
(27) Ying Zong said: "This poem not only counts for nothing, but also has heavy ghost feeling. Therefore, you must drink three cups of wine." ("The History of the Palace of the Ming Dynasty")

(28) During the banquet, when talking about Zhi Fansu, it can be supplemented by the co-owner, so as to eliminate the corrupt officials and enter the Qing dynasty. This not only can eliminate the anger, but also can achieve great merits. (Chapter 46 of "The History of the Ming Dynasty")

In order to fully explain the use of the Chinese sentence pattern "not only p, but also q" during the Republic of China, we take the fifteen ancient books before and after this period as examples in "Table II":

TABle II. The USE of Chinese SENTENCE PATtern "NOT ONLY P, BUt ALSO Q" IN THE REPUBLIC OF CHINA

\begin{tabular}{|c|c|c|c|c|c|}
\hline The title of books & not only $p$, also q & not only $p$, and also $q$ & not only $p$, but $q$ & not only $p$, and $q$ & not only $p$, and $q$ \\
\hline Ancient and Modern Love & 0 & 0 & 0 & 0 & 6 \\
\hline History of Han & 0 & 1 & 1 & 2 & 0 \\
\hline History of Tang Dynasty & 0 & 1 & 0 & 4 & 0 \\
\hline $\begin{array}{l}\text { The Third Talents of the Qing } \\
\text { Dynasty }\end{array}$ & 0 & 7 & 0 & 0 & 14 \\
\hline History of Song Dynasty & 0 & 3 & 0 & 2 & 0 \\
\hline History of Ming Dynasty & 0 & 5 & 0 & 2 & 1 \\
\hline History of Qing Dynasty & 0 & 3 & 0 & 2 & 0 \\
\hline The history of republic of China & 1 & 10 & 0 & 9 & 18 \\
\hline $\begin{array}{l}\text { Love Story of Imperial Court in } \\
\text { Han Dynasty }\end{array}$ & 0 & 1 & 0 & 0 & 1 \\
\hline $\begin{array}{c}\text { Love Story of Imperial Court in } \\
\text { Qing Dynasty }\end{array}$ & 1 & 5 & 0 & 0 & 3 \\
\hline Unofficial History of Wu Emperor & 1 & 0 & 0 & 0 & 1 \\
\hline Secret History of Qing Dynasty & 0 & 1 & 0 & 1 & 0 \\
\hline $\begin{array}{c}\text { Private Records of Studying in } \\
\text { Japan }\end{array}$ & 0 & 0 & 0 & 0 & 1 \\
\hline Unofficial History of Qing Dynasty & 1 & 1 & 0 & 0 & 0 \\
\hline Rickshaw Boy & 0 & 0 & 0 & 0 & 10 \\
\hline subtotal & 4 & 38 & 1 & 22 & 55 \\
\hline
\end{tabular}

It can be seen from "Table II" that during the Republic of China, the use of Chinese "not only p, but also q" sentence patterns increased significantly, and this period is the development period of this sentence pattern. At the same time, the use of Chinese "not only p, and q", "not only p, but q" sentence patterns has increased compared with the previous period, and the use of Chinese "not only p, also q" sentence patterns has not changed significantly from the previous period. The use of Chinese "not only p, and also q" sentence patterns has decreased compared with the previous period. However, the frequency of these sentences is not as good as the Chinese sentence "not only p, but also q".

In summary, the use of Chinese "not only p, but also q" sentence patterns was first seen in the Qing Dynasty and developed rapidly during the Republic of China.

\section{CONCLUSION}

The Chinese "not only p, but also q" sentence originated from the "not only $\mathrm{p}$, but q" format in the Western Han Dynasty, and it first appeared in "Theory the Song Dynasty". The diachronic evolution of the Chinese "not only $p$, but also q" sentence patterns has gone through a long period of time. It was formed in the Qing Dynasty and developed rapidly during the Republic of China.

\section{REFERENCES}

[1] Zhang Bin. Modern Chinese Descriptive Grammar [M]. Beijing: The Commercial Press, 2015.
[2] Zhou Gang. Conjunctions and related issues [M]. Hefei: Anhui Education Press, 2002.

[3] Xing Fuyi. Research on Chinese Complex Sentences[M]. Beijing: The Commercial Press, 2001.

[4] Zhu Dexi. Grammar Lecture [M]. Beijing: The Commercial Press, 1982.

[5] Xu Yangchun. Research on the Sentence Patterns of Modern Chinese Complex Sentences[M]. Beijing: China Social Sciences Publishing House, 2002

[6] Mo Chao, Lei Chengquan. General Theory of Related Words [M] Lanzhou: Gansu People's Publishing House, 2003.

[7] Chen Baoqin. On "After", "Yet", "Where", "And" "Also", "But" and "However" [J]. Research In Ancient Chinese Language, 1994 (03).

[8] Liu Licheng, Liu Yinglu. The rationale for the conjunctions of "not only" [J]. Chinese Language Learning, 2008 (03). 